http://dx.doi.org/10.1590/1678-4162-7451

Arq. Bras. Med. Vet. Zootec., v.67, n.4, p.1003-1008, 2015

\title{
Cryptococcus: isolamento ambiental e caracterização bioquímica
}

[Cryptococcus: environmental isolation and biochemical characterization]

\author{
E.C. Araújo Júnior, C.V. Táparo, C.Y. Uchida, M. Marinho*
}

Faculdade de Medicina Veterinária de Araçatuba - FMVA- Unesp - Araçatuba, SP

\section{RESUMO}

O gênero Cryptococcus caracteriza-se por ser uma levedura responsável por infecção sistêmica, causada pelas espécies Cryptococcus neoformans e Cryptococcus gattii. O fungo é encontrado em substratos de origem animal e vegetal, e a infecção ocorre com a inalação de basidiósporos ou leveduras desidratadas infectantes presentes no ambiente. O presente trabalho teve por objetivo pesquisar a existência de microfocos de Cryptococcus sp. em amostras ambientais da cidade de Araçatuba, São Paulo, com a finalidade de minimizar os riscos de contaminação do homem e dos animais, buscando o conhecimento da ecoepidemiologia do Cryptococcus. Foram colhidas 50 amostras oriundas de ocos e troncos de árvores (Cassia sp., Ficus sp., Caesalpinea peltophorides) de 10 locais representativos do perímetro urbano, as quais foram encaminhadas ao Laboratório de Bacteriologia e Micologia da Faculdade de Medicina Veterinária de Araçatuba-Unesp, onde foram processadas e semeadas em placas de Petri contendo ágar semente de Níger e Sabouraud dextrose com clorafenicol e incubadas à temperatura de $30^{\circ} \mathrm{C}$, por um período não inferior a cinco dias. Posteriormente, foram submetidas às provas bioquímicas: produção de urease, termotolerância a $37^{\circ} \mathrm{C}$ e quimiotipagem em ágar CGB (L-canavanina-glicina-azul de bromotimol). A análise dos resultados revelaram que 17 (34\%) dos cultivos foram positivos para o gênero Cryptococcus, sendo nove (18\%) para Cryptococcus gattii e oito (16\%) para Cryptococcus neoformans. Outras leveduras correlacionadas, como Rhodotorula sp. e Candida sp., também foram isoladas. Concluise que os basidiósporos de Cryptococcus encontram-se dispersos na natureza, constituindo microfocos ambientais, não vinculados necessariamente a um único hospedeiro.

Palavras-chave: árvore, criptococose, microbiologia ambiental, microfocos

\begin{abstract}
Cryptococcosis is an opportunistic fungal infection caused by Cryptococcus yeasts, especially C. neoformans and Cryptococcus gattii. The fungus is found in substrates of animal and vegetable origin, and infection occurs through inhalation and seedlings present in the environment. The present study aimed to investigate the existence of microfocus Cryptococcus sp. from the environmental samples of Araçatuba city, São Paulo, featuring new niches, by decoupling the direct relationship between fungus and host in order to minimize the risk of contamination of man and animals, understanding the ecoepidemiology of Cryptococcus. Fifty samples from hollows and tree trunks were harvested (Cassia $s p$., Ficus sp., Caesalpinea peltophorides) from ten representatives in the urban perimeter. The samples were immediately sent to the Laboratory of Bacteriology and Mycology, Faculty of Veterinary Medicine Araçatuba - Unesp where they were processed and plated on Petri dishes containing agar seed Niger and Sabouraud dextrose agar with chloramphenicol, incubated at $30^{\circ} \mathrm{C}$ for a period of no less than 5 days. Afterwards they were subimitted to biochemical tests: urease production, thermotolerance at $37^{\circ} \mathrm{C}$ and quimiotipagem in CGB agar (L-Canavanine-Glycine-Bromothymol blue). The results showed that 17 (34\%) cultures were positive for Cryptococcus, 9 (18\%) for Cryptococcus gattii and 8 (16\%) for Cryptococcus neoformans. Other yeast correlated as Rhodotorula $s p$. and Candida $s p$. were isolated. We conclude that the infectious propagules of Cryptococcus are dispersed in nature and constitute an environmental microfocus, not necessarily being bound to a single host.
\end{abstract}

Keywords: tree, cryptococcosis, environmental microbiology, microfocus

Recebido em 7 de março de 2014

Aceito em 4 de maio de 2015

*Autor para correspondência (corresponding author)

E-mail: mmarinho@fmva.unesp.br 


\section{INTRODUÇÃOO}

O gênero Cryptococcus caracteriza-se por leveduras encapsuladas que podem estar dispersas no ambiente, tendo como habitat natural lugares úmidos (Ribas et al., 2011). A Criptococose é uma micose sistêmica, cuja porta de entrada é via inalatória, causada por um complexo de fungos patogênicos do gênero Cryptococcus, que agride o homem e os animais (Brasil, 2012) e que ganhou relevância pelo seu caráter de infecção oportunista, acometendo pacientes imunocomprometidos ou não (Filiú et al., 2002).

O gênero Cryptococcus apresenta cerca de 70 espécies (Kurtzman et al., 2011) e, atualmente, duas dessas espécies são reconhecidas como patogênicas: Cryptococcus neoformans e Cryptococcus gattii. A primeira inclui os sorotipos A (variação grubii), D (var. neoformans) e AD (híbrida entre var. neoformans e $C$. gattii), e a segunda os sorotipos B e C (Ribas et al., 2011). As espécies e variedades se diferem em aspectos bioquímicos, biológicos, ecológicos, antigênicos e genéticos (Queiroz et al., 2008). O Cryptococcus neofomans, variedades $\mathrm{A}, \mathrm{D}$ e $\mathrm{AD}$, tem a capacidade de colonizar a mucosa do papo dos pombos, sem causar a doença, comportando-se como agente endossaprófito natural dessas aves (Filiú et al., 2002). O C. gattii é frequentemente isolado de plantas, estando associado a espécies nativas e exóticas de regiões tropicais e subtropicais (Lazera et al., 2000; Queiroz et al., 2008).

Sabe-se que as excretas de aves funcionam como uma fonte nutritiva para Cryptococcus. Entretanto, estudos demonstraram que C. gattii é raramente observado em fezes de aves, mesmo utilizando melhor a creatinina como fonte de nitrogênio, como a var. grubi e neoformans (Abegg et al., 2006).

A infecção pode ocorrer pela inalação de propágulos de origem ambiental (Levitz, 1991), representados por leveduras desidratadas, menores que $2 \mu \mathrm{m}$ de diâmetro, facilmente aerossolizadas (Filiú et al., 2002), em locais contaminados por excretas secas, pela ingestão de poeira e/ou de alimentos contaminados com as excretas de aves, sendo eventualmente eliminadas para o meio ambiente. Pela ação do ar, os propágulos contaminariam outras excretas de pombos não contaminadas (Casadevall e Perfect, 1998).

O isolamento de Cryptococcus spp. de excretas de psitacídeos (Filiú et al., 2002), passeriformes (Lugarini et al., 2008; Marinho et al., 2010), morcegos (Tencate et al., 2012), columbiformes (Cichon et al., 2011) e falconiformes (Cafarchia et al., 2006) tem sido relatado constantemente na literatura e muitas vezes associado ao hábito da ave de raspar e fragmentar pedaços de madeira e galhos (Filiú et al., 2002).

$\mathrm{O}$ isolamento do fungo de amostras ambientais vem sendo amplamente pesquisado, como demonstraram López-Martinez et. al. (1995), Lázera et al. (2000), Kobayashi et al. (2005), Reimão et al. (2007), Refojo et al. (2008) e Mazza et al. (2013), os quais determinaram novas fontes de transmissão, identificando outros nichos ecológicos para a levedura.

Alguns trabalhos associaram Cryptococcus neoformans ao pombo, criando uma constante associação entre fungo e hospedeiro (KwonChung e Bennett, 1984; Ferreira e Raso, 2012). Entretanto, Passoni (1999) afirma que o habitat primário para o Cryptococcus gattii pode ser espécies de plantas e madeira envelhecida, locais onde a levedura naturalmente desenvolve $\mathrm{o}$ estado sexuado e que, portanto, caracterizam um novo habitat natural, relacionando o microrganismo à madeira em decomposição de diferentes árvores tropicais nativas ou exóticas introduzidas no Brasil (Brasil, 2012), o que corrobora a permanência do Cryptococcus no ambiente. Esse fato é favorecido tanto pelo $C$. gattii quanto pelo $C$. neoformans pela capacidade de produzir lacase (fenol oxidase), que permite a colonização da madeira, principalmente em estado avançado de decomposição (Baltazar e Ribeiro, 2008).

O presente trabalho teve por objetivo investigar novos habitats para Cryptococcus sp. em amostras ambientais do município de Araçatuba, São Paulo, a fim de compreender melhor a ecoepidemiologia do microrganismo e conhecer novos nichos ambientais do patógeno para que, posteriormente, medidas preventivas possam ser elaboradas com o propósito de minimizar os riscos de contaminação humana. 


\section{MATERIAL E MÉTODOS}

Para verificar a ocorrência de leveduras com caráter patogênico de Cryptococcus spp., foram colhidas 50 amostras de 10 locais não protegidos (praças e parques), próximos às ruas movimentadas ou com um fluxo significativo de pessoas e animais, no período de agosto a dezembro de 2013. As amostras foram provenientes de fragmentos de troncos e material putrefado de ocos de árvores (Cassia sp., Ficus sp., Caesalpinea peltophorides), sem a presença de excretas de aves, por meio de raspagem com auxílio de curetas, máscaras e luvas. As amostras foram armazenadas em frascos plásticos estéreis, com tampa de rosca, e encaminhadas ao Laboratório de Bacteriologia e Micologia da Faculdade de Medicina Veterinária, UnespAraçatuba. As amostras foram processadas em câmara de fluxo laminar, onde $1 \mathrm{~g}$ da amostra foi macerada utilizando-se pistilo e gral. Posteriormente, o material foi colocado em um frasco Erlenmeyer de $125 \mathrm{~mL}$ contendo $50 \mathrm{~mL}$ de salina estéril a $0,9 \%$, e foi acrescido de cloranfenicol a $0,04 \%$. Após vedação do frasco com Parafilm ${ }^{\circledR}$, a amostra foi agitada em vortex de maneira vigorosa, por cinco minutos, para posteriormente se manter a solução por um período de repouso de 30 minutos, após o que foram transferidos $10 \mathrm{~mL}$ do sobrenadante para tubos e centrifugados por cinco minutos a 1500rpm. Foram descartados $9 \mathrm{~mL}$ do sobrenadante, e o sedimento foi homogeneizado no volume restante, procedendo-se com a semeadura em placas de Petri contendo meios de cultura de ágar semente de Níger e Sabouraud dextrose com cloranfenicol, sendo incubado a $30^{\circ} \mathrm{C}$ por um período não inferior a cinco dias. A leitura ocorria diariamente, e os repiques eram realizados, conforme necessário, para obtenção de isolados puros e exuberantes.

As colônias sugestivas de Cryptococcus spp., com coloração marrom-escura, foram repicadas em tubos com ágar Sabouraud para identificação e manutenção da amostra. Todas as colônias leveduriforme foram submetidas à coloração com tinta nanquim e lactofenol-azul-algodão para a análise morfológica das estruturas fúngicas. As colônias identificadas para o gênero Cryptococcus foram submetidas a testes bioquímicos.

Entre o gênero Cryptococcus, apenas $C$. neoformans e $C$. gattii são capazes de crescer a $37^{\circ} \mathrm{C}$. Para análise da termotolerância, as amostras foram repicadas em ágar Sabouraud, mantidas a $37^{\circ} \mathrm{C}$ por sete dias.

A detecção da enzima urease, a qual identifica o gênero Cryptococcus, foi analisada pela utilização do meio ureia-ágar-base (Christensen, 1946). Nessa reação, observa-se a hidrólise da ureia com produção de amônia e alcalinização do meio, o que provoca alteração do indicador de $\mathrm{pH}$ de neutro para básico, evidenciando-se, assim, uma coloração de tom róseo intenso. Os isolados foram repicados nesse meio e incubados a $30^{\circ} \mathrm{C}$ por cinco dias.

Para diferenciar as espécies de $C$. neoformans e C. gattii, foi utilizado o meio canavanina-glicinaazul de bromotimol (CGB) (Kwon-Chung et al., 1982). As colônias de C. gattii utilizam a glicina como fonte de carbono e nitrogênio e são resistentes à canavanina, mostrando uma coloração azul-cobalto, enquanto $C$. neoformans não demonstra mudança na coloração do meio. Os isolados foram repicados em meio CGB e incubados a $30^{\circ} \mathrm{C}$ por até cinco dias, observandose diariamente a coloração do meio.

As variáveis foram testadas pelo teste exato de Fisher e pelo teste qui-quadrado, sendo adotado o nível de significância de 5\%. Utilizou-se o programa SAS (2013).

\section{RESULTADOS E DISCUSSÃO}

Foram associadas as variáveis árvores e espécies de microrganismo $(\mathrm{P} \leq 0,8855)$; local e espécie de microrganismo $(\mathrm{P} \leq 0,2904)$, por meio do teste exato de Fisher. Para a análise de tendências, utilizou-se o teste qui-quadrado das variáveis tempo e espécie de microrganismo $(\mathrm{P} \leq 0,7466)$. As associações não foram significativas, ou seja, o Cryptococcus pode ser encontrado em diferentes locais, espécies de árvores e período do ano.

Das 50 amostras colhidas por meio de raspagem de troncos e ocos de árvores, 17 (34\%) dos cultivos foram positivos para o Cryptococcus, sendo nove (18\%) para Cryptococcus gattii e oito $(16 \%)$ para Cryptococcus neoformans. Outras leveduras correlacionadas, como Rhodotorula sp. e Candida sp., também foram isoladas. 
As amostras colhidas em seis locais de colheita $(60 \%)$ apresentaram crescimento puro e exuberante para uma única espécie de Cryptococcus, enquanto em outros três locais (30\%) houve crescimento associado das espécies de Cryptococcus neoformans e C. gattii. Em apenas um local especifico (Praça Dr. Jaime de Oliveira), a amostra resultou no cultivo negativo para o microrganismo estudado (Fig. 1). A maioria das amostras com cultivos associados para ambas as espécies foi proveniente de Caesalpinea peltophoroides (Sibipiruna), enquanto os cultivos isolados foram oriundos de Ficus sp. e Cassia sp. Ressalta-se que, em todos os locais, havia grande fluxo de pessoas e animais, inclusive no local onde não houve crescimento microbiológico.

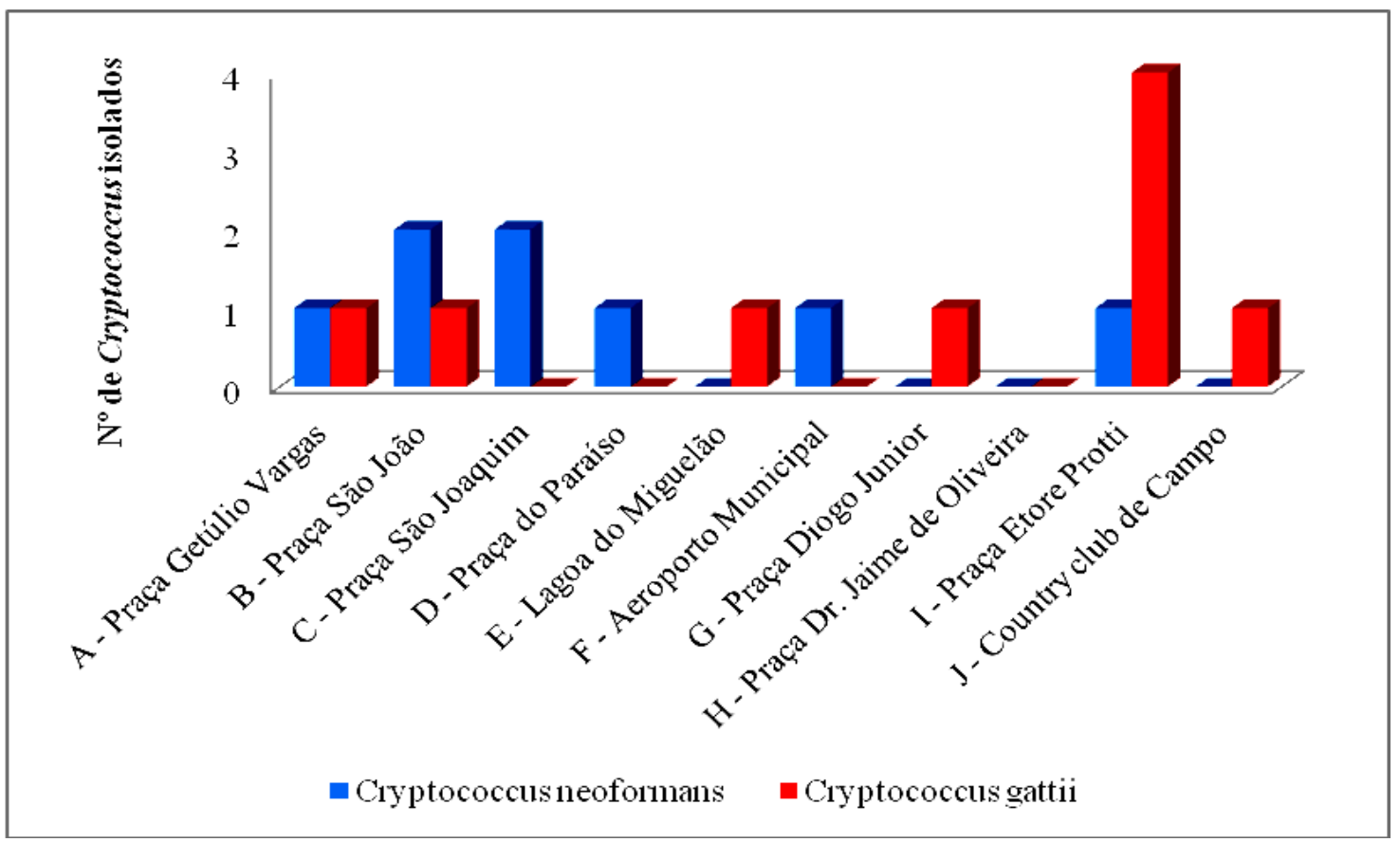

Figura 1. Leveduras do gênero Cryptococcus sp. isoladas de pontos estratégicos da cidade de Araçatuba, São Paulo, 2013.

Os resultados desta pesquisa confirmam o isolamento de Cryptococcus gatti e de $C$. neoformans de tronco de Cassia sp; tronco e oco de Ficus sp. e tronco de Caesalpinea peltophorides. Lázera et al. (2000), Baltazar e Ribeiro (2008) e Mazza et al. (2013) também obtiveram o isolamento de Cryptococcus spp. em diferentes espécies de árvores.

De acordo com Beheregaray et al. (2005), temperaturas superiores a $30^{\circ} \mathrm{C}$ diminuiriam a viabilidade da levedura no ambiente. Entretanto, as coletas foram realizadas entre agosto e dezembro, quando a temperatura média na cidade de Araçatuba oscilou entre 33 e $35^{\circ} \mathrm{C}$ (Prefeitura Municipal de Araçatuba, 2014), obtendo-se colônias puras e exuberantes. Há de se considerar, no entanto, que durante as colheitas, entre o período de agosto a meados de outubro, quando a cidade de Araçatuba, São Paulo, passou por momentos de baixa umidade com escassez de chuva, as colônias leveduriformes com características de Cryptococcus sp., na análise microscópica, apresentaram-se pequenas, dificultando a observação das estruturas morfológicas. Já no período de maior umidade, entre novembro e dezembro, as colônias sugestivas de Cryptococcus sp., na análise microscópica, apresentavam suas estruturas nítidas e de fácil visualização. A temperatura elevada associada à baixa umidade são fatores que podem contribuir para a inativação do microrganismo no ambiente.

Com relação ao binômio fungo - hospedeiro, $C$. gatti não tem sido isolado de pombos, e, como afirma Passoni (1999), o habitat primário para o microrganismo pode ser espécies de plantas e 
madeiras envelhecidas, dissociando, assim, a figura do pombo como hospedeiro.

O problema que agrava a existência de microfocos ambientais para o $C$. gattii fundamenta-se na virulência do patógeno que, geralmente, atua como agente primário para a Criptococose, independentemente do estado imunológico. De acordo com Correa et al. (1999), a infecção por $C$. gattii pode ainda permanecer quiescente por um longo período, infectando-se em uma fase precoce da vida (infância) para exteriorizar os sintomas em uma fase tardia. Segundo Swinne (1979), o $C$. neoformans encontra-se vinculado ao pombo, apresentando uma complexa interação entre o fungo, o ambiente e o hospedeiro. Entretanto há de se considerar a eventualidade com que o $C$. neoformans é eliminado com as excretas após o término do ciclo gastrintestinal. Destaca-se a sua permanência e viabilidade no ambiente, como a sua disseminação pela ação do vento, carreando os propágulos para outras excretas, adjacentes e presentes no solo (Casadevall e Perfect, 1998), como sendo fatores relevantes à formação de microfocos e à ampliação dos riscos de contaminação ambiental.

A presença de fungos correlacionados, como Candida sp. e Rhodotorula sp., também foi observada em excretas de psitacídeos (Lugarini et al., 2007), passeriformes (Marinho et al., 2010), fezes de morcegos (Tencate et al., 2012), corroborando o problema que envolve a permanência de excretas no ambiente, as quais constituem uma fonte nutritiva para as leveduras e ampliam os riscos de contaminação.

\section{CONCLUSÃO}

Conclui-se que as espécies vegetais presentes nas praças e nos parques da cidade de Araçatuba constituem microfocos para Cryptococcus spp, contribuindo, assim, para a contaminação ambiental e a dissociação exclusiva do binômio: pombo - C. neoformans.

\section{REFERÊNCIAS}

ABEGG, M.A.; CELLA, F.L.; FAGANELLO, J. et al. Cryptococcus neoformans and Cryptococcus gattii isolated from the excreta of psittaciformes in a southern Brazilian zoological garden. Mycopathologia, v.161, p.83-91, 2006.
BALTAZAR, L.M.; RIBEIRO, M.A. Primeiro isolamento ambiental de Cryptococcus gattii no Estado do Espírito Santo. Rev. Soc. Bras. Med. Trop., v.5, p.449-453, 2008.

BEHEREGARAY, W.K.; PÖPPL, A.G.; HARTFELDER, C.C. et al. Criptococose em um cão com envolvimento de linfonodos, pele, olhos e glândula mandibular. Rev. Univ. Rural, v.25, supl., p.252-253, 2005.

CASADEVALL, A.; PERFECT, J.R. Cryptococcus neoformans. Washington, DC: American Society for Microbiology Press, 1998. $541 \mathrm{p}$.

CAFARCHIA, C.; ROMITO, D.; IATTA, R. et al. Role of birds of prey as carriers and spreaders of Cryptococcus neoformans and other zoonotic yeasts. Med. Mycol., v.44, p.485-492, 2006.

CHRISTENSEN, W. B. Urea decomposition as a means of differentiating Proteus and paracolon cultures from each other and from Salmonella and Shigella types. J. Bacteriol., v.52, p.461-466, 1946.

CICHON, M.; VICENTE, V.A.; MURO, M.D. et al. Isolamento de Cryptococcus neoformans de amostras ambientais de Curitiba e região metropolitana (Paraná, Brasil) e testes de suscetibilidade frente a drogas antifúngicas. Rev. Bras. Anál. Clín., v.43, p.176-179, 2011.

CORREA, M.P.; OLIVEIRA, E.C.; DUARTE, R.R. et al. Cryptococcosis in children in the State of Para, Brazil. Rev. Soc. Bras. Med. Trop., v.32, p.505-508, 1999.

FERREIRA, V.L.; RASO, T.F. Survey of cryptococcal antingens in urban pigeons (Columbia livia) in São Paulo State, Brazil. J. Poultry Sci., v.11, p.1-4, 2012.

FILIÚ, W.F.O.; WANKE, B.; AGÜENA, S.M. et al. Cativeiro de aves como fonte de Cryptococcus neoformans na cidade de Campo Grande, Mato Grosso do Sul, Brasil. Rev. Soc. Bras. Med. Trop., v.35, p.591-595, 2002.

KOBAYASHI, C.C.B.A.; SOUZA, L.K.H.; FERNANDES, O.F.L. et al. Characterization of Cryptococcus neoformans isolated from urban environmental sources in Goiânia, Goiás, Brazil. Rev. Soc. Bras. Med. Trop., v.7, p.203-207, 2005. 
KURTZMAN, C.P.; FELL, J.W.; BOEKHOUT, T. Cryptococcus. In: KURTZMAN, C.P.; FELL, J.W.; BOEKHOUT, T. The yeasts: a taxonomic study. 5. ed. New York: ACM Press, 2011. p.1661-1662.

KWON-CHUNG, K.J.; BENNET, J.E. Epidemiologic differences between the two varieties of Cryptococcus neoformans. Am. J. Epidemiol., v.120, p.123-130, 1984.

KWON-CHUNG, K.J.; POLACHECK, I.; BENNETT, J.E. Improved diagnostic medium for separation of Cryptococcus neoformans var. neoformans (serotype A and D) and Cryptococcus neoformans var. gattii (serotype B and C). J. Clin.. Microbiol., v.15, p.535-537, 1982.

LAZERA, M.S.; SALMITO-CAVALCANTI, M.A.; LONDERO, A.T et al. Possible primary ecological niche of Cryptococcus neoformans. Med. Mycol., v.38, p.379-383, 2000.

LEVITZ, S.M. The ecology of Cryptococcus neoformans and the epidemiology of cryptococcosis. Rev. Infect. Dis., v.13, n.6, p.1163-1169, 1991.

LÓPEZ-MARTINEZ, R.; CASTAÑÓNOLIVARES, L.R. Isolation of Cryptococcus neoformans from bird droppings fruits and vegetable in Mexico city. Micopathologia, v.129, p.25-28, 1995.

LUGARINI, C.; CONDAS, L.A.S.; SORESINI, G.C et al. Screening of antigenemia and isolation of Cryptococcus neoformans and Cryptococcus gattii from cloaca and crop of birds in the state of Paraná, Brazil. Pesqu. Vet. Bras., v.28, p.341344, 2008.

MARINHO, M.; TAPARO, C.V.; SILVA, B.G et al. Microbiota fúngica de passeriformes de cativeiros da região noroeste do Estado de São Paulo.Vet. Zootec., v.2, p.288-292, 2010.

MAZZA, M.; REFOJO, N.; BOSCOBORGEAT, M.E et al. Cryptococcus gattii in urban from cities in North-eastern Argentina. Micoses, v.56, p.646-650, 2013.
PASSONI, L.F.C. Wood, animals and human beings as reservoirs for human Cryptococcus neoformans infection. Rev. Iberoam. Micol.. v.16, p.77-81, 1999.

PREFEITURA DO MUNICÍPIO DE ARAÇATUBA. Portal da prefeitura do município de Araçatuba. Disponível em: http://www.aracatuba.sp.gov.br/ Acesso em: 08 jan. 2014.

QUEIROZ, J.P.A. F.; SOUSA, F.D.N.; LAGE, R.A et al. Criptococcose: uma revisão bibliográfica. Acta Vet. Bras., v.2, p.32-8, 2008.

REFOJO, N.; PERROTA, M. ; BRUDNY, R et al. Isolation of Cryptococcus neoformans and Cryptococcus gattii from trunk hollows of living trees in Buenos Aires City, Argentina. Med. Micol, v.47, p.1-8, 2008.

REIMÃO, J.Q.; DRUMMOND, E.D; TERCETI, M.S et al. Isolation of Cryptococcus neoformans from hollows of living trees in the city of Alfenas, MG, Brazil. Mycoses, v. 50, p.261-264, 2007.

RIBAS, R.C.; BAEZA, L.C.; RIBEIRO, F.H. M.. Isolation of Cryptococcus spp. in excrements of pigeons (Columba sp.) in the Maringa city, PR, Brazil. Arq. Ciênc. Saúde Unipar, v.15, p.45-50, 2011

SAS System, release 9.3. Cary, NC: SAS Institute Inc., 2013.

SWINNE, D. Cryptococcus neoformans and the epidemiology of criptococcosis. Ann. Soc. Med. Trop., v.59, p.285-299, 1979.

TENCATE, L.N.; TAPARO, C.V.; CARVALHO, C. et al. Estudo da microbiota fúngica gastrintestinal de morcegos (Mammalia, Chiroptera) da região noroeste do estado de São Paulo: potencial zoonótico. Braz. J. Vet. Res. Anim. Sci., v.49, p.146-152, 2012.

VIGILÂNCIA e epidemiológica da Criptococose. Brasília, DF: Ministério da Saúde, 2012. 